\title{
DESCARGAS ATMOSFÉRICAS E INTERRUPÇÕES DE ENERGIA ELÉTRICA NA ÁREA DA CHESF: RELAÇÃO COM VARIÁVEIS ATMOSFÉRICAS EM ANOS DE EL NIÑO E LA NIÑA
}

\author{
WENDELL RONDINELLI GOMES FARIAS ${ }^{1}$ MAGALY DE FÁTIMA CORREIA ${ }^{2}$
}

\author{
${ }^{1}$ Instituto Nacional de Pesquisas Espaciais - INPE \\ ${ }^{2}$ Universidade Federal de Campina Grande - UFCG \\ wfarias@dge.inpe.br \\ magaly@dca.ufcg.edu.br
}

Recebido Janeiro 2007 - Aceito Janeiro 2008

\begin{abstract}
RESUMO
Condições climáticas e ambientais influenciam diretamente no desenvolvimento e intensificação de tempestades seguidas de descargas atmosféricas, e são responsáveis por interrupções no fornecimento de energia elétrica no Nordeste do Brasil. Este estudo tem como objetivo estabelecer relações entre variáveis meteorológicas, que permitam equacionar a influência de condições ambientais na intensificação de atividade convectiva responsável por interrupções no fornecimento de energia elétrica por descargas atmosféricas em anos de El Niño e La Nina. As análises são restritas à área de atuação da CHESF (Companhia Hidro Elétrica do São Francisco), a qual tem grande parte das Linhas de Transmissão de energia instaladas no semi-árido do Nordeste do Brasil. O método de componentes principais escolhido como principal ferramenta de análise permitiu isolar padrões significativos de umidade, vento e temperatura no domínio analisado. Vórtices ciclônicos em altos níveis (VCAN), foram os principais responsáveis pelo desenvolvimento de sistemas precipitantes intensos e ocorrências de falhas transitórias no sistema de transmissão da CHESF.
\end{abstract}

Palavras chave: Descargas Atmosféricas; Componentes Principais; Vórtices Ciclônicos de Altos Níveis.

\begin{abstract}
BREAKS IN ELECTRIC POWER SUPPLY DUE TO ATMOSPHERIC DISCHARGES IN CHESF MANAGEMENT AREA.

Climatic and environmental conditions directly influence the development and the intensification of storms followed by atmospheric discharges and they are responsible for interruptions in the electric energy supply in the Northeast of Brazil. This study has as objective to establish relations between meteorological variables that allow formulating the influence of environmental conditions to the intensification of convective activity responsible for interruptions of the electric energy supply during years of El Niño and La Nina. The analyses are restricted to the CHESF (Companhia Hidro Elétrica do São Francisco) activity areas having most of its energy Transmission Lines installed in the semi-arid of Northeastern Brazil. The method of principal component analysis chosen as main analysis tool, allowed isolating significant atmospheric patters of moisture, wind and air temperature over the analyzed domain. Upper Tropospheric Cyclonic Vortices (UTCV) had been responsible for the development of intense precipitation systems and occurrences of transient failures in the CHESF transmission system.
\end{abstract}

Keywords: Atmospheric discharge, principal component and Upper Tropospheric Cyclonic Vortices. 


\section{INTRODUÇÃO}

O desempenho dos sistemas de energia elétrica é bastante suscetível a variações no clima, e muito vulnerável aos eventos extremos de chuva. No Brasil, episódios de interrupção no fornecimento de energia elétrica decorrentes de ventos fortes e descargas elétricas associados com tempestades severas são bastante freqüentes nas regiões sul e sudeste do país. No entanto, na região Nordeste, apesar da baixa freqüência de sistemas severos também se observa danos materiais e interrupções no sistema de distribuição de energia associadas com descargas atmosféricas. Estas ocorrências são registradas em situações de intensa atividade convectiva e representam uma das principais causas de desligamentos na área de transmissão da CHESF.

A identificação de padrões atmosféricos responsáveis pela ocorrência de eventos extremos de chuva e o conhecimento sobre os efeitos da variabilidade climática, na demanda de energia elétrica são de fundamental importância nas atividades relacionadas ao planejamento e elaboração de projetos de operação e manutenção do sistema elétrico. Estudos desta natureza podem gerar informações de grande utilidade em ações preventivas contra os fenômenos naturais que afetam diretamente o setor elétrico do país.

A CHESF é responsável pelo gerenciamento de $90 \%$ da eletrificação do Nordeste e representa o principal gestor dos recursos hídricos da região, regularizando a vazão e controlando cheias. Possui um dos maiores sistemas de transmissão em alta tensão no país com aproximadamente 18000 quilômetros de linhas instaladas (CHESF, 2003). A adequação de projetos de Linhas de Transmissão (LT's) à realidade climática regional é fundamental na busca de sistemas mais econômicos e mais seguros.

O Nordeste brasileiro (NE) situado aproximadamente entre as latitudes de $1^{\circ}$ e $18^{\circ} \mathrm{S}$ e longitudes de $34^{\circ}$ e $48^{\circ} \mathrm{W}$, possui uma grande diversidade climática. Pode-se observar desde o clima semi-árido com chuvas anuais abaixo de 500 $\mathrm{mm}$ no interior da região até o clima chuvoso encontrado na costa leste com totais anuais acima de $1500 \mathrm{~mm}$. A distribuição espacial das chuvas na região torna-se complexa em função dos diversos sistemas de circulação atmosférica atuantes. A ZCIT (Zona de Convergência Intertropical) destaca-se por ter influência direta modulando a distribuição sazonal de precipitação pluviométrica sobre o Atlântico Equatorial, parte do norte do Nordeste brasileiro (Nobre e Shuckla, 1996) da estação chuvosa principalmente no setor norte do nordeste. Atua no verão e início do outono (Uvo, 1989). Outros sistemas meteorológicos, entretanto, afetam de forma significativa à intensidade e distribuição das chuvas no Nordeste. Os vórtices ciclônicos de altos níveis (VCAN) são sistemas que influenciam todo o Nordeste, atuando no final da primavera, verão e início do outono. Estão associados com volumes de chuva substanciais registrados principalmente no mês de janeiro caracterizado como o período de maior ocorrência destes sistemas. (Kousky e Gan, 1981). A zona de convergência do Atlântico Sul (ZCAS) influencia o clima no oeste e sul do Nordeste, durante o verão, associada à incursão de sistemas frontais austrais (Satyamurty et al., 1998). Outro sistema de grande escala que influencia as condições atmosféricas da região são os distúrbios de leste (Espinoza, 1996), principais responsáveis pela precipitação na estação chuvosa do leste do Nordeste, no outono e inverno do hemisfério sul. Assim como os sistemas de grande escala, merecem destaque o Anticiclone do Atlântico Sul, a convecção na Amazônia e o ramo subsidente da ZCIT por serem responsáveis por movimentos de subsidência na região $\mathrm{NE}$ e pela grande incidência de inversões térmicas que inibem o desenvolvimento de sistemas precipitantes (Correia et al. 2006; Silva Aragão et al., 2000; Gandu e Silva Dias, 1998).

Fenômenos globais como El Nino (EN) e La Niña (LN) afetam consideravelmente os padrões meteorológicos de algumas regiões. O semi-árido do Nordeste está entre as localidades mais atingidas pela ação destes fenômenos. Um dos efeitos climáticos mais conhecidos, em episódios de El Niño, é a redução drástica na quantidade de chuvas na região (Aragão, 1998). Entretanto, esse efeito de grande escala não impede que fatores locais em muitas situações sejam responsáveis pela evolução de sistemas meteorológicos intensos e ocorrências de falhas no sistema de transmissão de energia produzidas por descargas elétricas. Por outro lado, episódios de La Niña favorecem a precipitação acima da média climatológica em boa parte do Nordeste e principalmente no setor leste com o avanço das frentes frias no litoral da Bahia, Sergipe e Alagoas, e chuvas acima da média no semi-árido nordestino (FUNCEME, 2003).

Neste sentido, o objetivo principal deste estudo é estabelecer relações entre variáveis meteorológicas, que permitam equacionar a influência de condições atmosféricas em interrupções no fornecimento de energia elétrica decorrentes de descargas atmosféricas com base em registros de eventos de atividade convectiva intensa em anos de El Niño e La Niña intensos. O método de componentes principais foi escolhido como ferramenta de análise.

A região foco deste estudo não dispõe de sensores de detecção de raios nem de radares meteorológicos (Banda $\mathrm{C}$ ou Banda S) capazes de monitorar em tempo real sistemas precipitantes intensos. A única série de imagens com alta resolução temporal e espacial é composta de informações obtidas na região com o radar banda $\mathrm{C}$ de Petrolina (PE) na estação chuvosa de 1985 (Correia, 1989; Silva Aragão et al., 2000). No entanto, um banco de dados contendo informações recentes sobre causas de falhas no sistema de transmissão da 
CHESF permitiu a realização desta pesquisa com resultados importantes para o setor ambiental e de energia.

\section{MATERIAL E MÉTODOS}

A principal fonte de informações usada nesta pesquisa é constituída por registros de falhas transitórias no sistema de transmissão da CHESF. Esse banco de dados contém informações sobre as causas de interrupções de energia, data e horário do evento. Vendavais, poluição e descargas atmosféricas estão entre as causas mais importantes de corte de energia. O conjunto de dados é constituído por um período de quinze anos, entre 1988 e 2002. Para realização deste trabalho foram selecionados apenas casos cujas ocorrências de falhas estiveram associadas com descargas atmosféricas. O conjunto de dados utilizado foi obtido através de registros de falhas transitórias e permanentes detectadas pelo sistema de distribuição nas linhas de transmissão da CHESF. A grande motivação para a pesquisa como também a escolha dos eventos analisados surgiu da constatação de falhas por descargas atmosféricas em anos, que coincidentemente se destacaram pela redução substancial no total pluviométrico em relação à média climatológica regional causando sérios transtornos à economia decorrente do fenômeno El Niño.

A chuva na região Nordeste é predominantemente de natureza convectiva, provém de sistemas isolados (organizados ou não) e mesmo em meses com precipitação acima da média, a distribuição da chuva no tempo é bastante irregular e ocorre normalmente em poucos dias do mês.

Dentro deste contexto, a atividade inicial do estudo consistiu do processamento das informações sobre falhas no sistema de transmissão de energia coincidentes com a ocorrência de eventos de precipitação intensa.

Foram utilizados ainda, dados do NCEP (National Center for Environmental Prediction) em pontos de grade de 2,5 $\mathrm{X}$ $2,5^{\circ}$ de resolução espacial para a componente zonal e meridional do vento, temperatura do ar e umidade específica, imagens de satélites nas bandas espectrais do visível e infravermelho (com ênfase na área que abrange a região Nordeste do Brasil) e registros pluviométricos de estações situadas na área de atuação da CHESF.

A escolha do período de estudo foi definida em duas etapas. A primeira foi constituída pela determinação de anos sob a influência dos fenômenos El Niño e La Niña e indicativo de falhas por descarga atmosférica, a partir das informações da CHESF e de dados climatológicos.

$\mathrm{Na}$ etapa seguinte foram definidos os episódios de falhas a serem analisados. A opção mais adequada para o estudo foi selecionar meses com o maior número de eventos de interrupções no fornecimento de energia por descargas atmosféricas ocorridos em anos de El Niño e La Niña classificados como intensos. Para efeito de comparação entre padrões atmosféricos foram priorizados aspectos de grande escala (condições sinóticas semelhantes).

\section{1 - Base de dados}

Para avaliar a associação entre condições atmosféricas e interrupções no fornecimento de energia é preciso lidar com bases de dados diferentes. Uma das maiores dificuldades para estruturar a base necessária à análise estatística foi encontrada no processo de mapeamento das localidades afetadas por descargas atmosféricas na área da CHESF. Nos eventos de falhas transitórias ocorridos no período analisado não foi possível determinar a localização exata atingida por raios. Em situações em que toda a linha é afetada o problema foi corrigido automaticamente. Apenas em episódios de falhas permanentes houve o deslocamento de uma equipe de manutenção até o local da ocorrência, e assim foi possível obter as coordenadas do setor afetado. Portanto, os dados sobre ocorrências de falhas utilizados neste trabalho, não são referenciados geograficamente como no caso de registros meteorológicos feitos em estações de superfície identificadas através da latitude e longitude. Os registros contêm informações sobre as linhas de transmissão com dimensões bastante variáveis cuja extensão do trecho de linha afetado e que passa no local atingido pela descarga atmosférica pode abranger vários estados. As coordenadas das subestações foram extraídas diretamente de um mapa do Sistema elétrico da região Nordeste. No entanto, a localização de setores atingidos pelas descargas atmosféricas foi feita de forma subjetiva. Na maioria dos casos foi considerada uma posição aproximada obtida a partir das coordenadas geográficas de cidades situadas na região do trecho afetado.

\subsection{Análise estatística}

O grau de influência das variáveis atmosféricas no desenvolvimento de tempestades e ocorrência de descargas elétricas, seja isoladamente ou resultante da interação entre elas, varia consideravelmente dependendo da região e do período analisado. Na maioria dos casos está associado com mudanças significativas no padrão de circulação atmosférica, no teor de umidade do ar, na pressão atmosférica e na temperatura do ar (Barbosa E Correia, 2006; Farias 2005). Entretanto, o grau de influência de cada variável isoladamente ou resultante da interação entre elas, varia consideravelmente dependendo da região e do período analisado.

Para explicar a estrutura de dependência entre as variáveis dominantes na ocorrência desses eventos, foram estimados modelos de análise fatorial com base na matriz de 

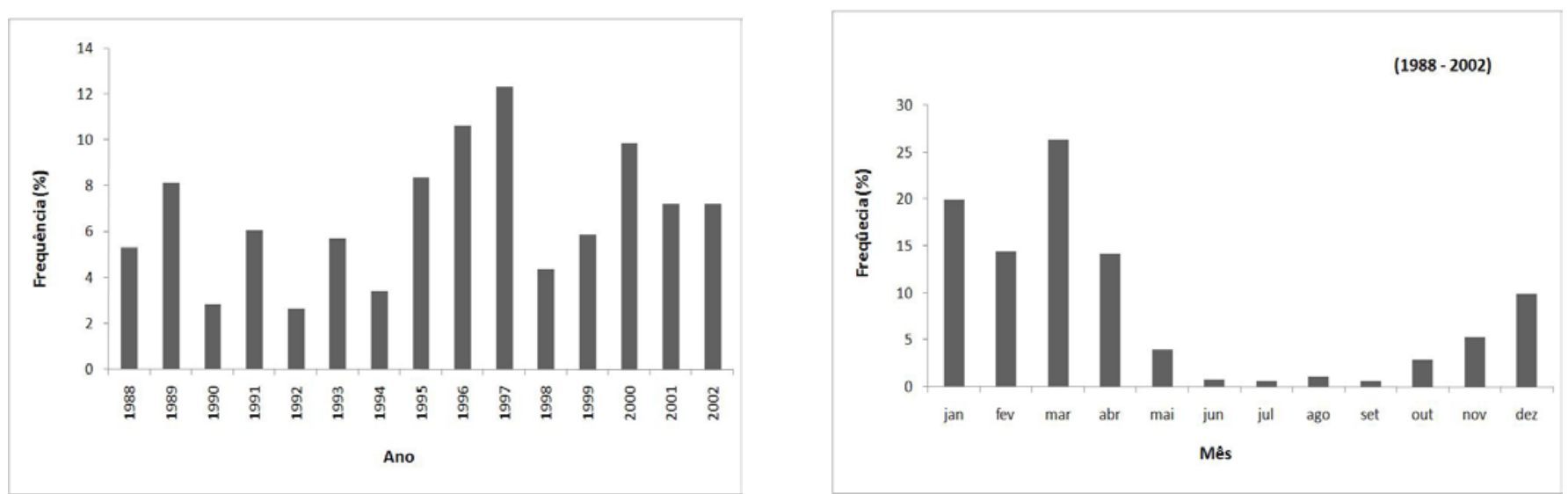

Figura 1 - Distribuição anual (a) e mensal (b) das ocorrências de falhas por descargas atmosféricas entre 1988 e 2002, no sistema de transmissão da CHESF. (Fonte dos dados: CHESF)

correlação pelo método de componentes principais. A vantagem deste método é que não há pressuposição da normalidade das variáveis envolvidas. Os fatores são obtidos a partir da matriz de covariância. No processo de decomposição obtêm-se cargas fatoriais que indicam quanto cada variável está associada a cada fator. Os autovalores refletem a importância de cada um deles e representam as variâncias das componentes principais. Uma descrição mais detalhada do método pode ser encontrada em Farias (2005).

\section{RESULTADOS E DISCUSSÕES}

A freqüência anual e mensal de falhas por descargas atmosféricas entre 1988 e 2002, ocorrido no sistema de transmissão de energia elétrica da CHESF (Figura 1), é mostrada nas Figuras 1a e 1b. O ano de 1997 destaca-se por apresentar a maior concentração de eventos no período. O comportamento sazonal com maior concentração no período chuvoso é evidente no histograma apresentado na Figura 1b. Cerca de $74 \%$ dos casos foram observados de janeiro a abril, sendo que $30 \%$ deles foram registrados só no mês de março.

Percebe-se na Figura 1a, um aumento substancial na ocorrência de falhas em episódios de La Niña (1988/1989, 1995/1996, 1999/2000) quando comparado com períodos sob a influência do fenômeno EL Niño (1989/1990, 1991/1992 e 1997/1998). Este resultado sugere que nos anos de La Niña a área com atividade convectiva intensa é mais freqüente e mais abrangente do que nos anos de El Niño. As análises apresentadas neste trabalho são referentes aos meses de dezembro de 1997 (El Nino) e janeiro de 2000 (La Nina).

\subsection{El Niño}

No ano de 1997 a CHESF registrou 66 interrupções no fornecimento de energia por descargas atmosféricas sendo que

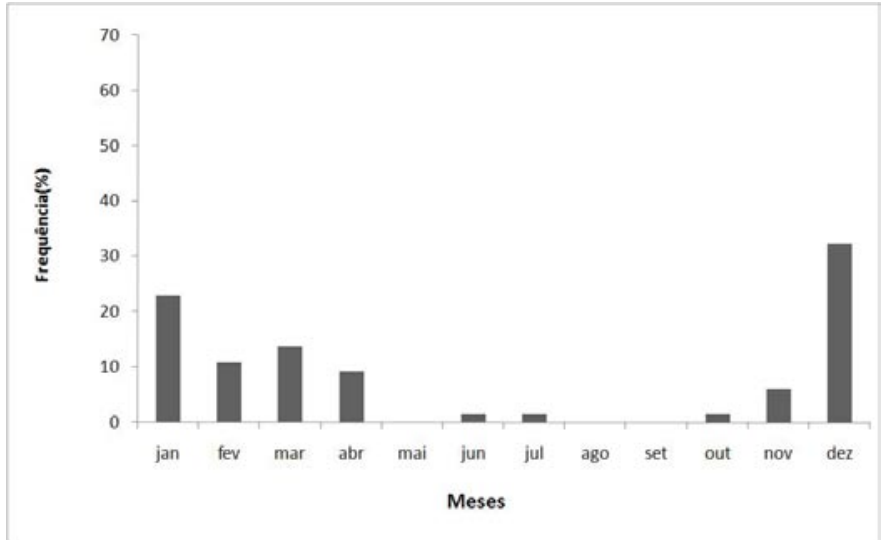

Figura 2 - Distribuição mensal das ocorrências de falhas por descargas atmosféricas para o ano de 1997 no sistema de transmissão da CHESF. (Fonte dos dados: CHESF).

mais da metade destas falhas ocorreram nos meses de janeiro (24\%) e dezembro (32\%) (Figura 2).

No início do ano as condições atmosféricas observadas eram de La Niña. No entanto, a partir do mês de julho, os efeitos do El Niño foram perceptíveis em diversas regiões do país. As chuvas ficaram abaixo da média em várias localidades das regiões Norte e Nordeste (http://www.cptec.inpe.br). Foram identificadas 21 ocorrências de interrupções de energia por descargas atmosféricas nos dias 11, 13, 14, 20, 21 e 26 de dezembro de 1997, caracterizando seis eventos de atividade convectiva intensa. Sendo que, os dias 20 e 21 se destacaram por apresentar o maior número de interrupções, principalmente no trecho entre Campina Grande (PB) e Santa Cruz (RN). O trecho de linha "Campina Grande - Santa Cruz" com uma extensão aproximada de $117,3 \mathrm{~km}$, pode ser visto no esquema ilustrado na Figura 3.

A Figura 4 mostra a área da Paraíba afetada por descargas atmosféricas e os histogramas com o total diário da precipitação 


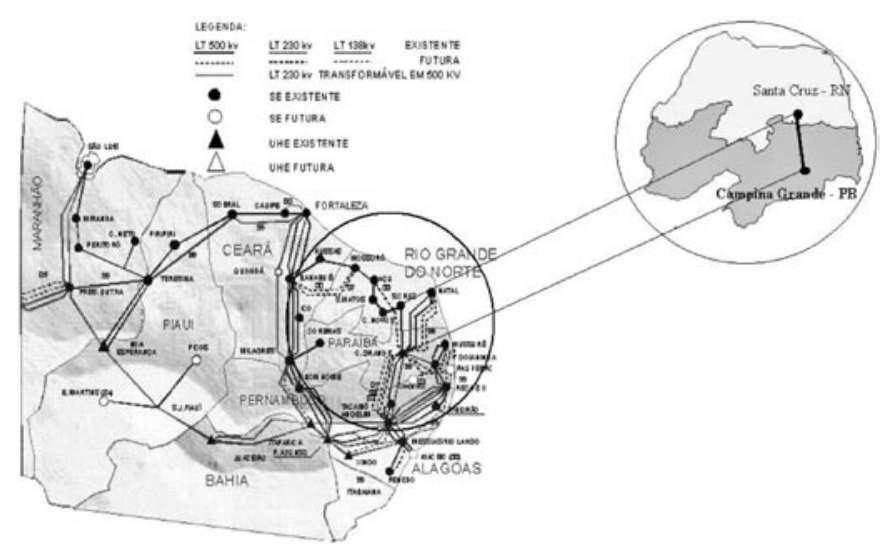

Figura 3 - Área coberta pelo Sistema de Transmissão da CHESF. A região no detalhe mostra a localização do trecho de linha Campina Grande (PB) - Santa Cruz (RN).

em dezembro de 1997, observado nas estações situadas no trecho entre $\mathrm{CG}$ e SC. Nota-se que as chuvas que atingiram esta área ocorreram preferencialmente entre os dias 20 e 23 do mês.

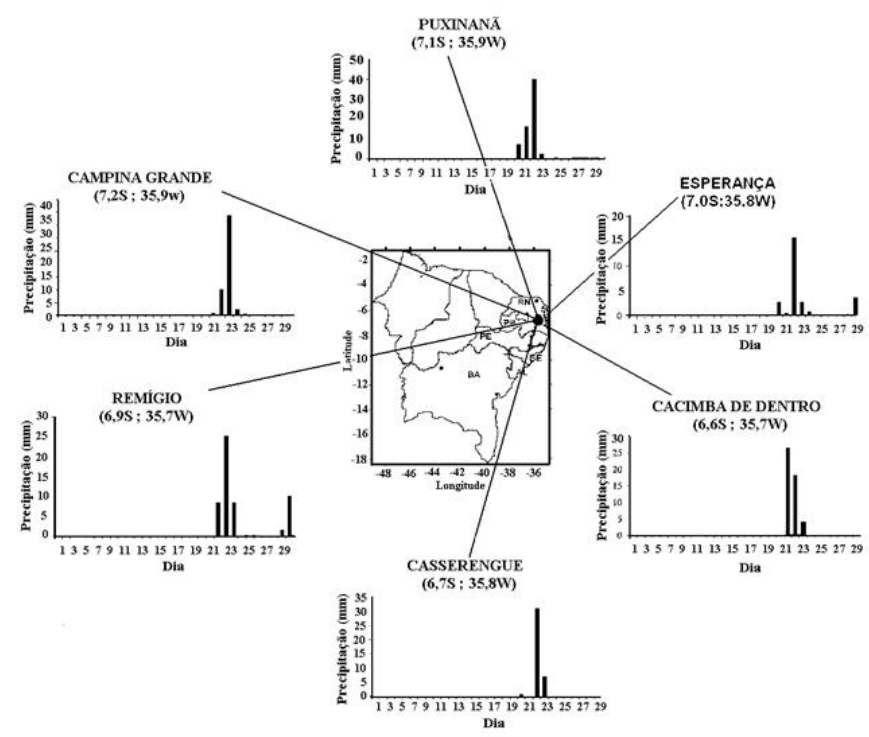

Figura 4 - Distribuição espacial do total diário de precipitação em dezembro de 1997 para postos pluviométricos próximos aos trechos afetados entre Campina Grande e Santa Cruz. (Fonte dos dados: CHESF e LMRS).

Segundo dados do CPTEC, em dezembro de 1997 observaram-se anomalias de TSM (Temperatura da Superfície do Mar) acima da média no setor sul do Atlântico Tropical e TSMs próximas da média no setor norte. Durante quase todo o mês a região Nordeste esteve sob influência de Vórtices Ciclônicos de Altos Níveis. As condições meteorológicas associadas com o terceiro vórtice entre os dias 16 e 23 que atuou na região foram favoráveis à ocorrência de atividade convectiva intensa e chuva forte na área das linhas de transmissão de 138 e
$230 \mathrm{kV}$, principalmente no trecho entre Campina Grande - PB (CG) e Santa Cruz - RN (SC).

Imagens de satélite obtidas nos 20 e 21 de dezembro de 1997 são mostradas na Figura 5. Observa-se que algumas regiões foram bastante afetadas pela atividade convectiva associada ao VCAN incluindo o nordeste da Bahia e os estados de Pernambuco, Paraíba e Rio Grande do Norte.

\subsubsection{Analise de Componentes Principais}

A ACP foi aplicada aos dados de vento nos níveis de 925,500 e $200 \mathrm{hPa}$, e da umidade específica e temperatura em $925 \mathrm{hPa}$ para o período de dias e horários com eventos de falhas por descarga atmosférica. Uma síntese dos eventos de falhas analisados neste estudo é apresentada na Tabela 1.

Tabela 1 - Eventos de falhas por descarga atmosférica no período de análise.

\begin{tabular}{|c|c|c|c|c|}
\hline ANO & $\begin{array}{c}\text { Total anual de } \\
\text { Falhas (no) }\end{array}$ & $\begin{array}{l}\text { Periodo analisado } \\
\text { (dias / mês) }\end{array}$ & $\begin{array}{c}\text { Interrupções no } \\
\text { Periodo (n") }\end{array}$ & Episídio \\
\hline \multirow[t]{2}{*}{1997} & 65 & $11 ; 13 ; 14 ; 20 ; 21 ; 26$ & 21 & El Niño \\
\hline & & Dezembro & & \\
\hline \multirow[t]{2}{*}{2000} & 52 & $01,05,13,15,20,21,24$ & 13 & La Niña \\
\hline & & Janeiro & & \\
\hline
\end{tabular}

A contribuição das três componentes significativas é mostrada na Tabela 2. Observa-se que as três CP's juntas explicam $81,1 \%, 72,4 \%$ e $73,9 \%$ da variabilidade do vento em 200,500 e $925 \mathrm{hPa}$, respectivamente. Para umidade específica em $925 \mathrm{hPa}$ a variância acumulada explica $89,6 \%$ da variabilidade total, e no caso da temperatura em $925 \mathrm{hPa}$ o valor acumulado é de $94,2 \%$.

Tabela 2 - Variância explicada (\%) e variância acumulada (\%) para as primeiras três componentes principais.

\begin{tabular}{|c|c|c|c|c|c|}
\hline var. expı. & & $v e n t o$ & & umıa. esp. & $1 \mathrm{cmp}$. ao ar \\
\hline$(h P a)$ & 200 & 500 & 925 & 925 & 925 \\
\hline CP1 & 50,81 & 42,59 & 31,36 & 31,55 & 35,22 \\
\hline CP2 & 17,05 & 18,08 & 28,72 & 30,08 & 21,84 \\
\hline CP3 & 13,81 & 11,74 & 13,88 & 27,94 & 27,11 \\
\hline Acum. & 81,05 & 72,41 & 73,96 & 89,56 & 94,17 \\
\hline
\end{tabular}

O grau de relação entre as variáveis, vento $(\mathrm{U}$ e $\mathrm{V})$, umidade específica (UM) e temperatura do ar (T) e suas componentes principais é mostrado na Figura 6. Foi verificado que a $\mathrm{CP} 1$ possui alta correlação com a componente zonal em 200 e $500 \mathrm{hPa}$ para todos os eventos. A relação é inversa no caso da componente meridional do vento.

No caso da umidade específica, em $925 \mathrm{hPa}$, a primeira componente (31,6\% da variabilidade total dos dados) apresentou 


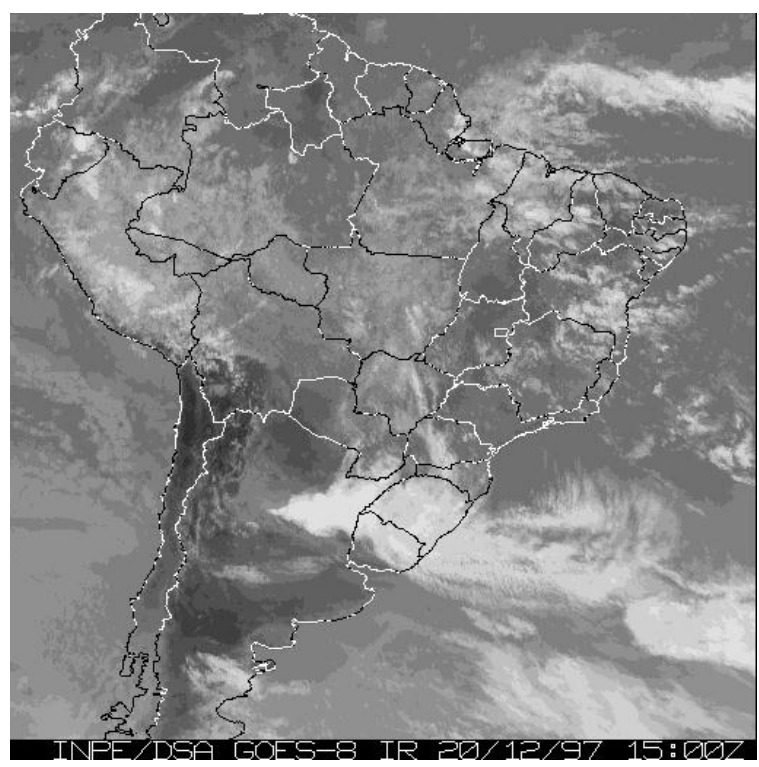

a)

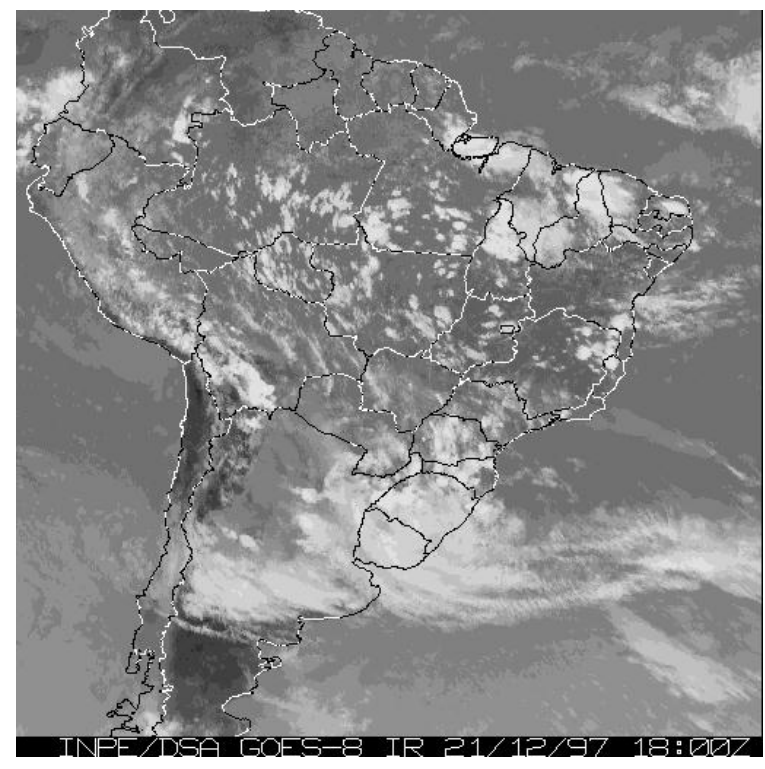

c)

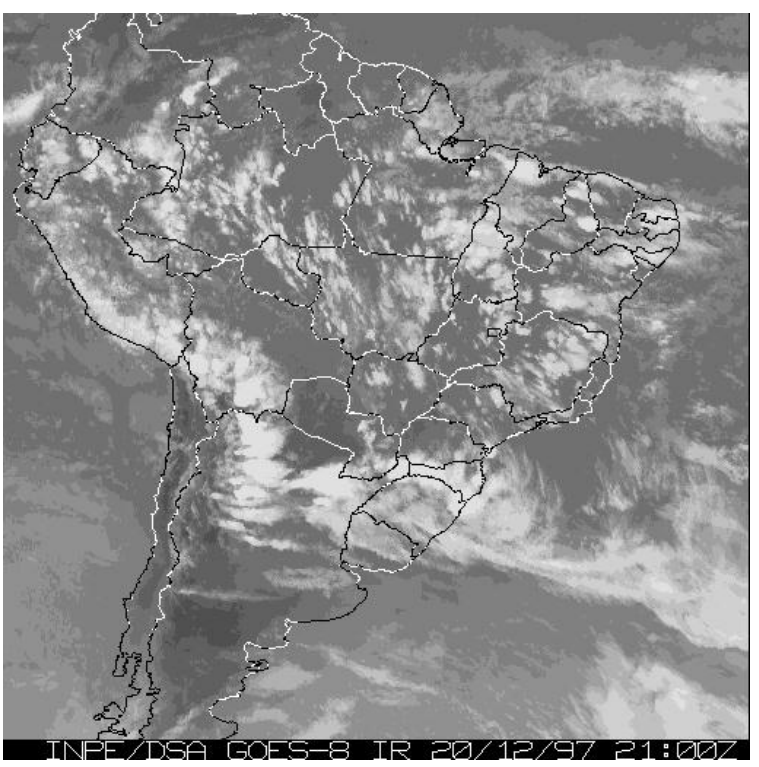

b)



d)

Figura 5 - Imagens do satélite GOES 8, no canal infravermelho para o dia 20/12/1997 nos horários das: a) 15:00UTC e b) 21:00UTC e para o dia 21/12/1997 no horário das: c) 18:00UTC e d) 21:00UTC (d).

forte correlação com os eventos 20 e 21 de dezembro (Fig. 6d) com valores entre 08 e 09 . Estes coeficientes indicam que a CP1 foi bastante representativa para concentração de umidade específica ocorrida nos eventos dos dias 20 e 21 de dezembro de 1997, ou seja, a maior concentração de umidade específica esteve entre os eventos dos dias 20 e 21. Da Figura $6 \mathrm{c}$ observa-se que para temperatura em $925 \mathrm{hPa}$, os eventos 20 e 21 estão mais bem correlacionados com a CP2. Estes resultados refletem a influência de mecanismos em escala local e regional no desenvolvimento e intensificação de sistemas convectivos em episódios de El Niño.
O coeficiente de correlação entre as variáveis correspondentes pode ser entendido como o valor do produto interno dos vetores que unem dois pontos em $\mathrm{R}^{\mathrm{n}}$, onde $\mathrm{R}$ é a matriz de correlação entre variáveis e o $\mathrm{n}$ é o número de observações ou dados. A matriz de correlação R é dada por:

$$
R=\frac{1}{n-1}(Z)^{t}(Z)
$$


onde $\mathrm{Z}$ é a matriz de dados originais ( $\mathrm{n} \mathrm{k}$ ) em que $\mathrm{n}$ é o número de observações e k é o número de variáveis de um determinado campo. Assim, a análise das proximidades ou oposições entre variáveis é feita em termos de correlações.

AACP permitiu separar grupos de variáveis, que juntas expressam situações atmosféricas específicas. Esses agrupamentos são claramente observados na Tabela 3. A associação entre o vento zonal e meridional nos níveis de 200 e $500 \mathrm{hPa}\left(\mathrm{U}_{200}\right.$ e $\left.\mathrm{U}_{500}\right)$ e o vento meridional em superfície $\left(V_{925}\right)$ é bem representada pela CP1 independente do evento.

Os eventos mais significativos durante o mês de dezembro ocorreram nos dias 20 e 21, os quais foram caracterizados por fortes temporais acompanhados de interrupções de energia por descarga atmosférica na região entre Campina Grande e Santa Cruz. A CP1 mostra uma forte associação entre o vento zonal e meridional nos níveis de 200 e $500 \mathrm{hPa}\left(\mathrm{U}_{200}\right.$ e $\left.\mathrm{U}_{500}\right)$, o vento meridional em superfície $\left(\mathrm{V}_{925}\right)$ e a umidade específica e temperatura em $925 \mathrm{hPa}\left(\mathrm{q}_{925}, \mathrm{~T}_{925}\right)$.

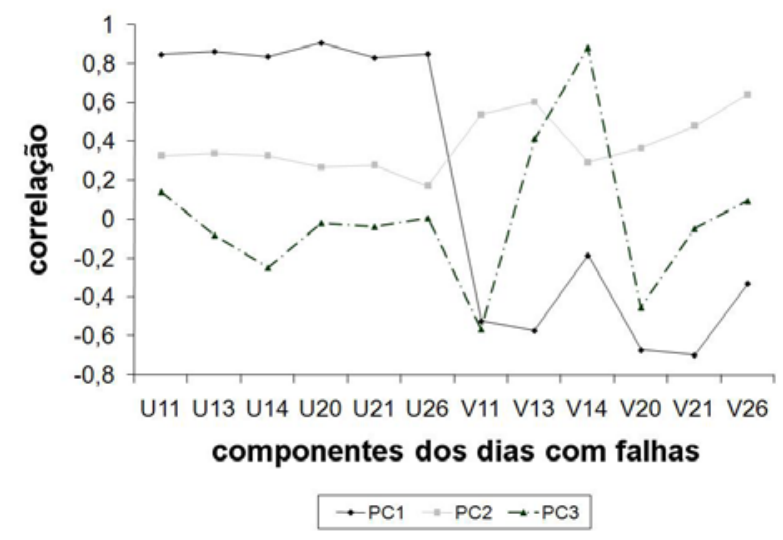

(a) $200 \mathrm{hPa}$

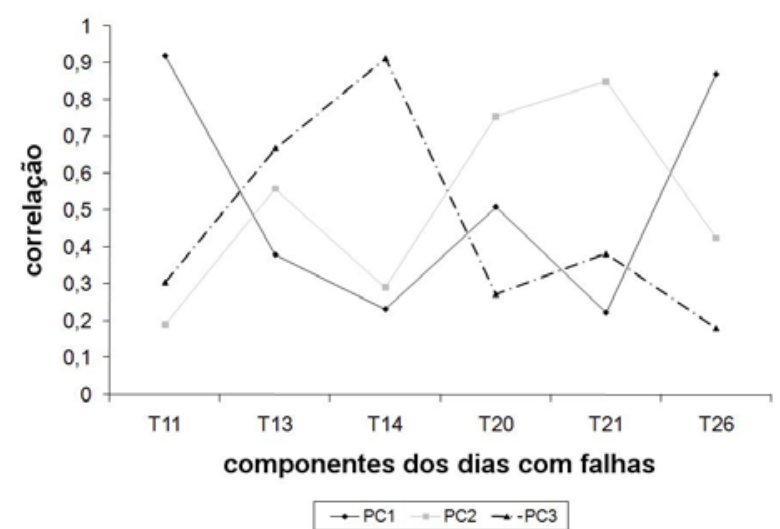

(c) $925 \mathrm{hPa}$
A associação entre variáveis em níveis atmosféricos distintos reflete a interação entre sistemas de circulação em diferentes escalas. Essa interaçãoé necessária ao desenvolvimento, organização e manutenção da convecção associada com VCAN.

A predominância da componente zonal em 200 e 500 $\mathrm{hPa}$ em todos os eventos indica o controle da escala maior. A presença da umidade específica em $925 \mathrm{hPa}$ no grupo de variáveis associadas à $\mathrm{CP} 1$ principalmente nos eventos 20 e 21, como também nos outros eventos caracterizados por falta de energia devido a descargas atmosféricas é apontado como sendo a razão mais importante na explicação da maior concentração de chuvas observadas entre 20 e 23 de dezembro no trecho CG - SC (Campina Grande - Santa Cruz).

As Figuras 7a e $7 b$ apresentam a distribuição espacial dos pesos relacionados aos escores da CP1, calculados para a umidade específica nos dias com eventos de falta por descarga atmosférica no mês de dezembro de 1997 e a média da umidade específica nos mesmos eventos, respectivamente. As regiões

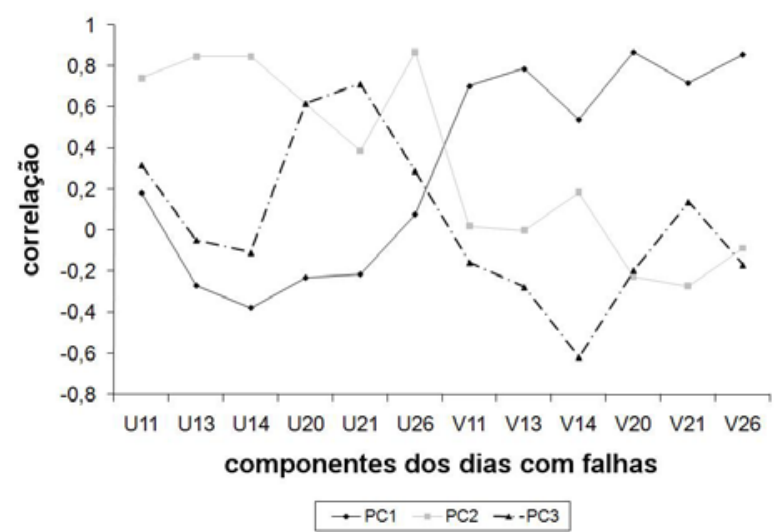

(b) $925 \mathrm{hPa}$

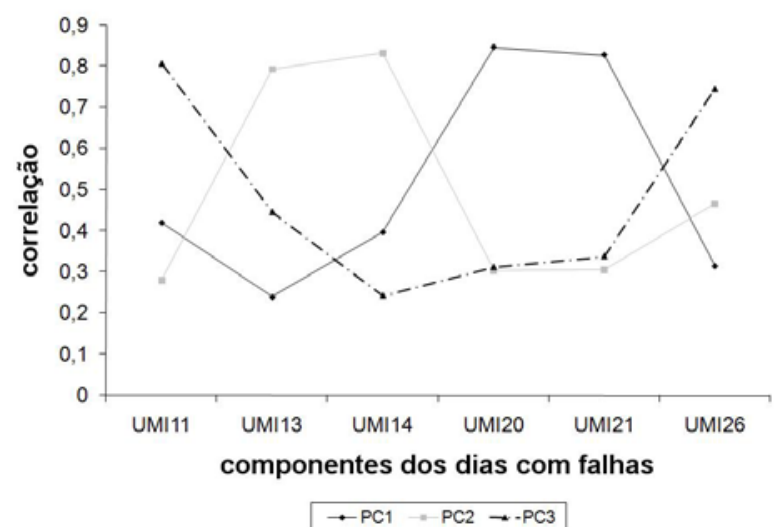

(d) $925 \mathrm{hPa}$

Figura 6 - Série temporal das CP's: (a) componentes zonal e meridional do vento em $200 \mathrm{hPa}$, (b)componentes zonal e meridional do vento em $925 \mathrm{hPa}$, temperatura do ar em $925 \mathrm{hPa}$ e umidade específica em $925 \mathrm{hPa}$. 
Tabela 3 - Agrupamento de variáveis segundo a ACP para os eventos de falhas no período El Niño (EL): CP1

\begin{tabular}{cccccc}
\hline DIA 11 & DIA 13 & DIA 14 & DIA 20 & DIA 21 & DIA 26 \\
\hline $\mathrm{U}_{200} ; \mathrm{U}_{500}$ & $\mathrm{U}_{200} ; \mathrm{U}_{500}$ & $\mathrm{U}_{200} ; \mathrm{U}_{500}$ & $\mathrm{U}_{200} ; \mathrm{U}_{500}$ & $\mathrm{U}_{200} ; \mathrm{U}_{500}$ & $\mathrm{U}_{200} ; \mathrm{U}_{500}$ \\
$\mathrm{~V}_{925} ; \mathrm{T}_{925}$ & $\mathrm{~V}_{925}$ & $\mathrm{~V}_{925}$ & $\mathrm{~V}_{925} ; \mathrm{q}_{925}$ & $\mathrm{~V}_{925} ; \mathrm{q}_{925}$ & $\mathrm{~V}_{925} ; \mathrm{T}_{925}$ \\
\hline
\end{tabular}

em tons mais claros estão associadas a valores negativos, o que significa dizer que nessas regiões existe um déficit de umidade. Enquanto as regiões de tons mais escuros estão associadas a pesos positivos, indicando que nessas áreas há um excesso de umidade que será tão maior quanto maior forem os seus valores (pesos) a ela atribuídos.

A comparação entre as Figuras $7 \mathrm{a}$ e $7 \mathrm{~b}$ evidencia a eficiência do método de ACP. Não existe qualquer indicativo sobre teor de vapor mais elevado no setor leste do NE no campo médio da umidade específica. Entretanto, observa-se nitidamente na CP1 (Figura 7a) um núcleo com máximos valores positivos sobre os Estados da Paraíba e Rio Grande do Norte. Os coeficientes positivos vistos na CP1 refletem a intensidade desse padrão e indicam que há um aumento de umidade nos baixos níveis (anomalia positiva). A ocorrência de algum mecanismo de meso ou grande escala que provoque



a) o levantamento desta massa de ar úmido é suficiente para dar início à formação de SC.

A distribuição espacial da $\mathrm{CP} 1$ aplicada para o evento do dia 20 para o vento em 200, 500 e $925 \mathrm{hPa}$ (não apresentados nesse trabalho) evidenciam uma intensificação dos ventos de sul em $925 \mathrm{hPa}$. Essa intensificação favorece a ascensão de ar e formação de nuvens de tempestade na região. Nos níveis superiores, os padrões indicam a intensificação de ventos de oeste em 200hPa sobre o NE e de ventos de leste em 500hPa.

Esse comportamento caracteriza a presença de cisalhamento vertical do vento (intensidade e direção) fundamental na organização e intensificação de SC. A distribuição espacial da $\mathrm{CP} 2$ para a temperatura do ar em $925 \mathrm{hPa}$ para o evento 20 é mostrada na Figura 8. Os coeficientes que indicam a intensidade deste padrão mostram um dipolo de temperatura centrado na região NE. Esse resultado reforça

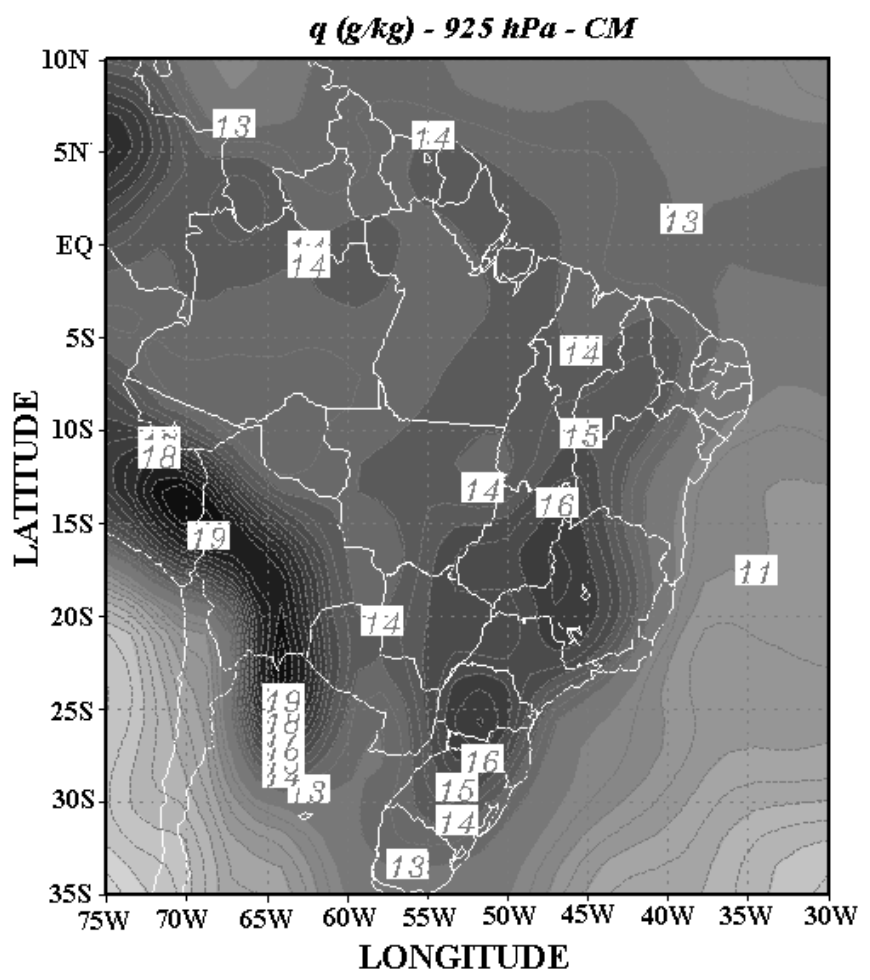

b)

Figura 7 - Configuração espacial da CP1 da umidade específica em $925 \mathrm{hPa}$ para os eventos com desligamentos de energia elétrica por descarga atmosférica (a). Configuração espacial do campo médio da umidade específica em $925 \mathrm{hPa}$ (b). 
as anomalias representadas no primeiro modo. Aquecimento diferencial está diretamente relacionado com gradiente de pressão, e conseqüentemente com intensificação das circulações nos baixos níveis.

\subsection{La Niña}

Durante o ano de 2000 foram registradas 51 falhas transitórias por descargas atmosféricas, sendo a maior concentração no mês de fevereiro com $28,8 \%$ das falhas ( 15 registros), seguido do mês de janeiro com $25 \%$ das ocorrências (13 registros de falhas). Sendo que para o mês de janeiro as interrupções de energia por descargas atmosféricas ocorreram nos dias 01, 05, 13, 15, 20,21 e 24 (Figura 9).

As falhas por descargas atmosféricas decorrentes da atividade convectiva ocorrida neste mês de janeiro de 2000, estiveram mais distribuídas na região $\mathrm{NE}$, do que para o ano de El Niño com maior concentração na parte leste da região.

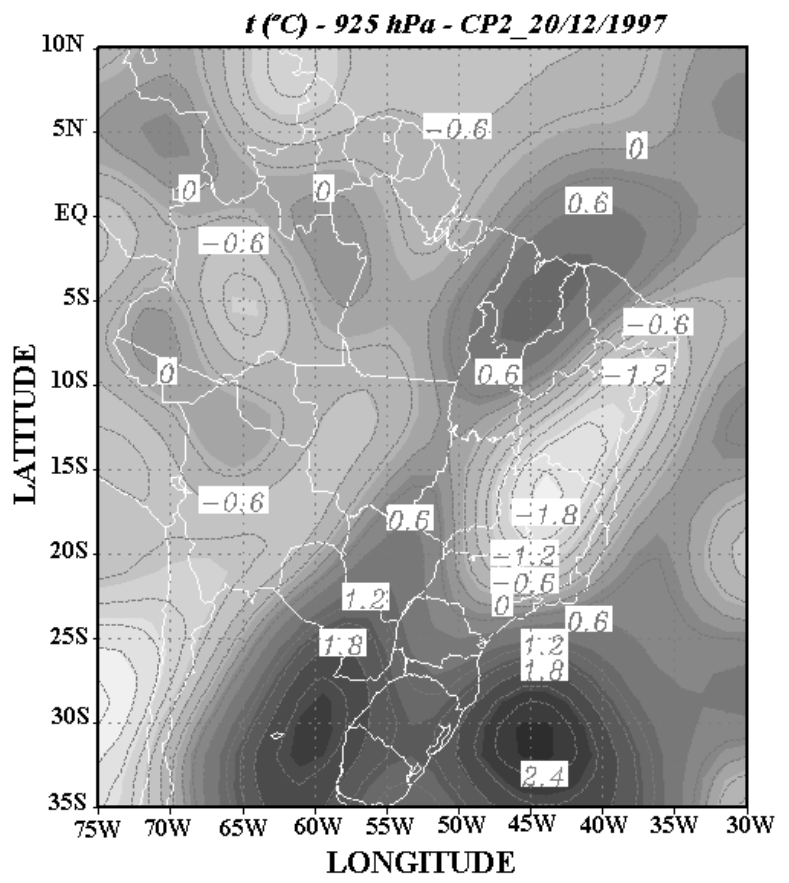

Figura 8 - Configuração espacial da CP2 para temperatura do ar em $925 \mathrm{hPa}$ no evento ocorrido no dia 20 de dezembro de 1997.

A nebulosidade associada aos sistemas que atuaram sobre o nordeste nos eventos de descarga atmosférica nos dias 20 e 21 de janeiro de 2000 pode ser vista nas imagens de satélite mostradas na Figura 10.

\subsubsection{Análise de Componentes Principais}

A ACP foi aplicada para as mesmas variáveis nos respectivos níveis. A contribuição das três componentes mais

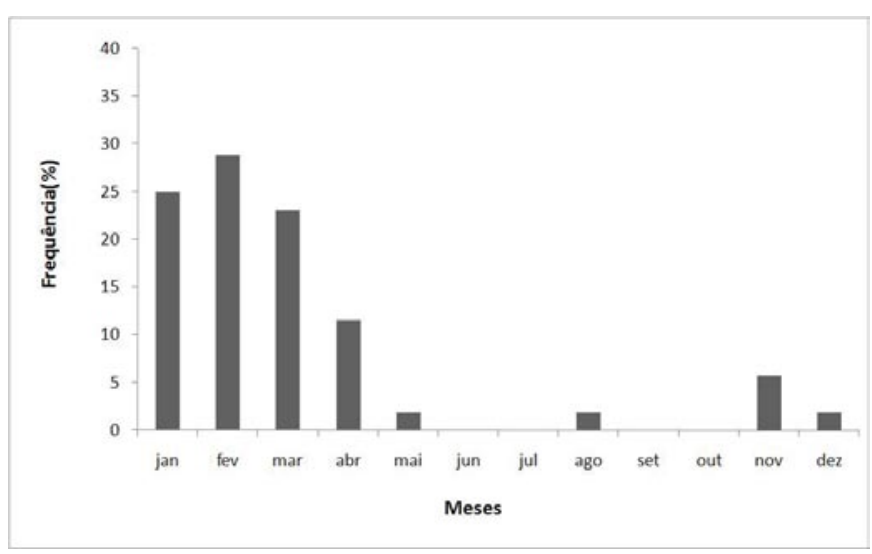

Figura 9 - Freqüência da ocorrência de falhas transitórias por descarga atmosférica durante o ano de 2000. (Fonte de dados: CHESF)

significativas é mostrada na Tabela 4. Observa-se que as três CPs juntas explicam 73,80\%, 58,71\% e 70,91\% da variabilidade do vento em 200, 500 e $925 \mathrm{hPa}$, respectivamente. No caso da umidade específica em $925 \mathrm{hPa}$, a variância acumulada explica $92,82 \%$ da variabilidade total e para temperatura em $925 \mathrm{hPa}$ o valor acumulado é de $94,76 \%$. O comportamento temporal das três componentes mais significativas pode ser visto na Figura 11.

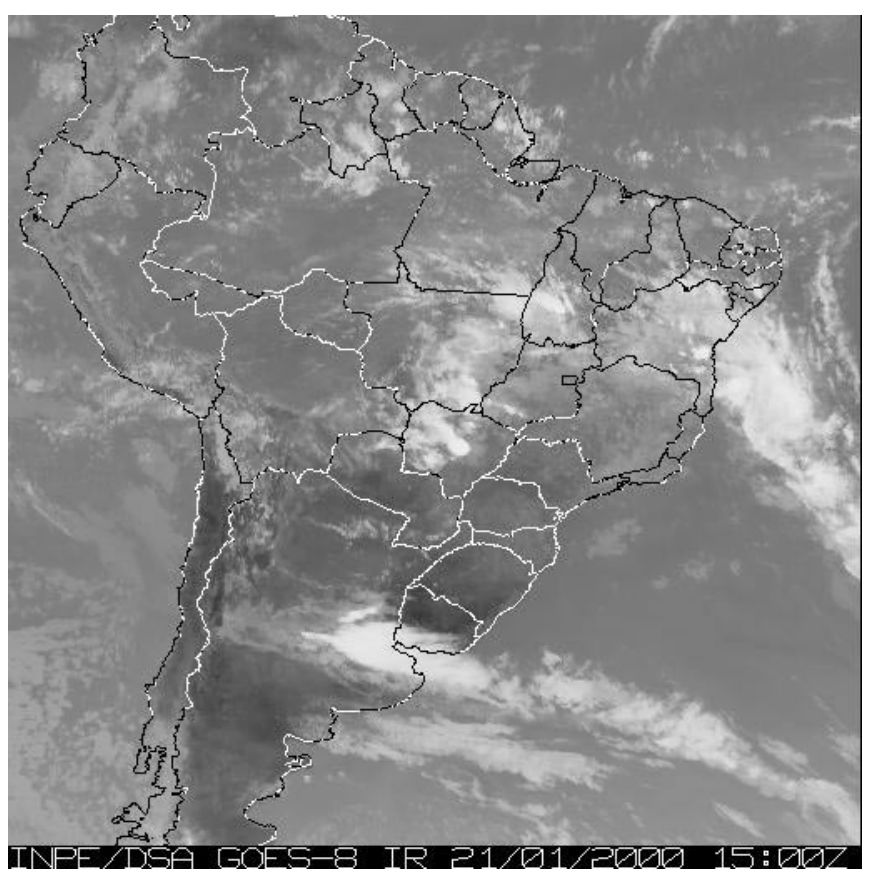

Figura 10 - Imagens do satélite geoestacionário GOES 8 no canal infravermelho para os dia 20 no horários 15:00Z (a) e dia 21 no horário das 18:00Z. (Fonte: INPE/DAS). 


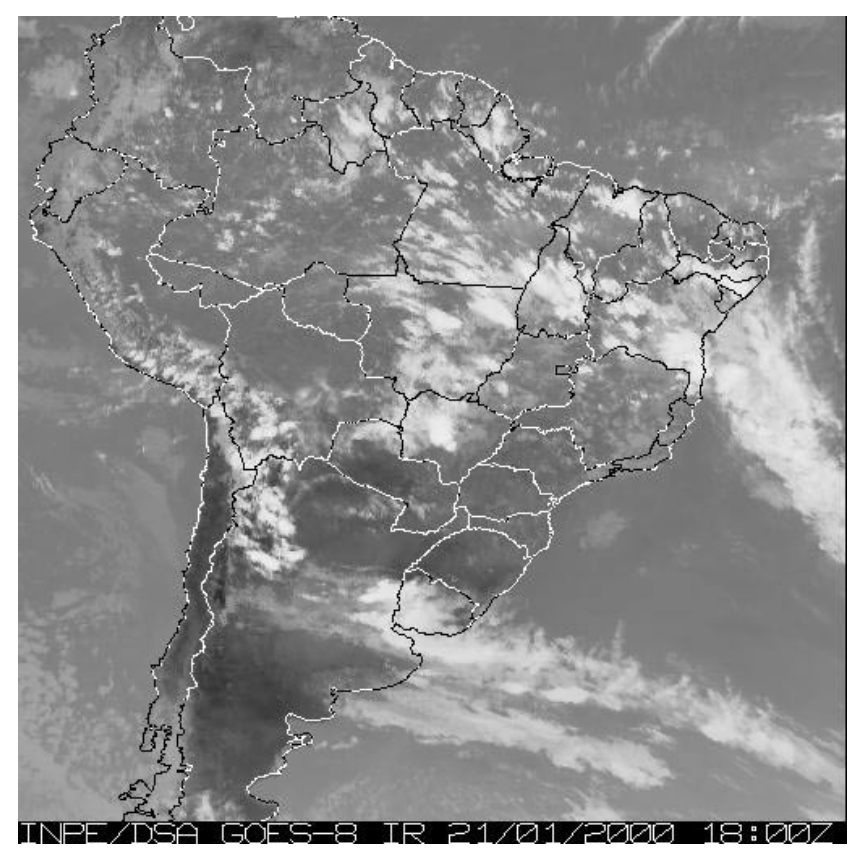

Figura 10 (Continuação) - Imagens do satélite geoestacionário GOES 8 no canal infravermelho para os dia 20 no horários 15:00Z (a) e dia 21 no horário das 18:00Z. (Fonte: INPE/DAS).

No que se refere ao grau de relação entre as variáveis, vento, umidade específica e temperatura do ar nos episódios de falhas e suas componentes, identifica-se que a CP1 apresenta alta correlação com a componente zonal nos três níveis, diferentemente dos eventos em situação de El Nino, onde em $925 \mathrm{hPa}$ a CP1 possui alta correlação com a componente meridional. Para a temperatura do ar e para a umidade específica a CP1 apresenta altas correlações para os eventos ocorridos nos dia 20 e 21.

Assim como para o período de EN, uma melhor visualização da associação entre as variáveis nos dias com interrupção de energia para o período $\mathrm{LN}$, os agrupamentos obtidos com a ACP são mostrados na Tabela 5.

As Figuras 12 e 13 mostram a configuração espacial da CP1 da umidade específica e da temperatura em $925 \mathrm{hPa}$ para o evento 20 janeiro de 2000 (período LN). Os núcleos positivos de umidade específica na região NE indicam alto teor de umidade nos baixos níveis (anomalia positiva).

Tabela 4 - Variância explicada (\%) e variância acumulada (\%) para as primeiras três componentes principais

\begin{tabular}{|c|c|c|c|c|c|}
\hline Var. Expl. & & Vento & & Umid. Esp. & Temp. do Ar \\
\hline$(h P a)$ & 200 & 500 & 925 & 925 & 92.5 \\
\hline CP1 & 40,14 & 31,88 & 32,11 & 34,47 & 38,39 \\
\hline CP2 & 22,93 & 15,79 & 19,41 & 30,09 & 29,01 \\
\hline $\mathrm{CP3}$ & 10,72 & 11,04 & 19,39 & 27,27 & 27,35 \\
\hline Acum. & 73,80 & 58,71 & 70,91 & 92,82 & 94,76 \\
\hline
\end{tabular}
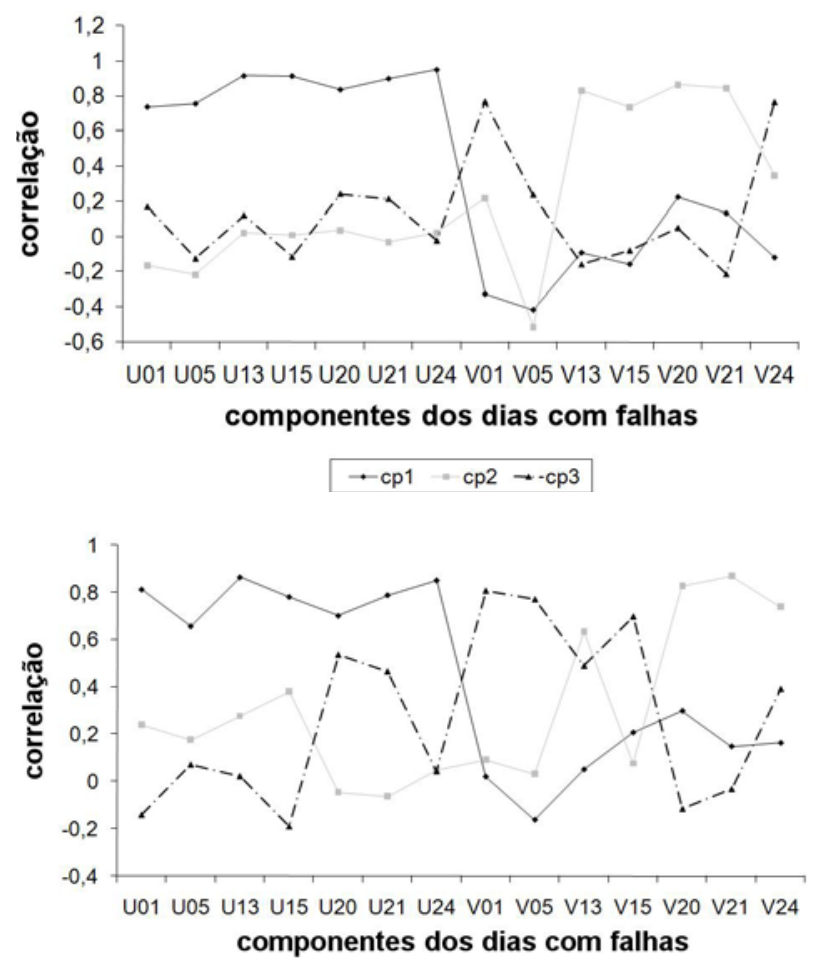

$\rightarrow \mathrm{CP} 1 \rightarrow \mathrm{CP} 2 \rightarrow-\mathrm{CP} 3$

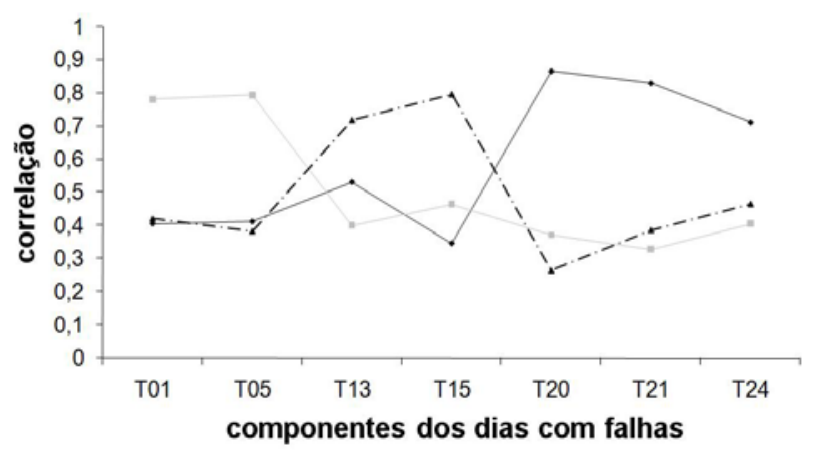

$\rightarrow \mathrm{CP} 1 \rightarrow \mathrm{CP} 2 \rightarrow-\mathrm{CP} 3$

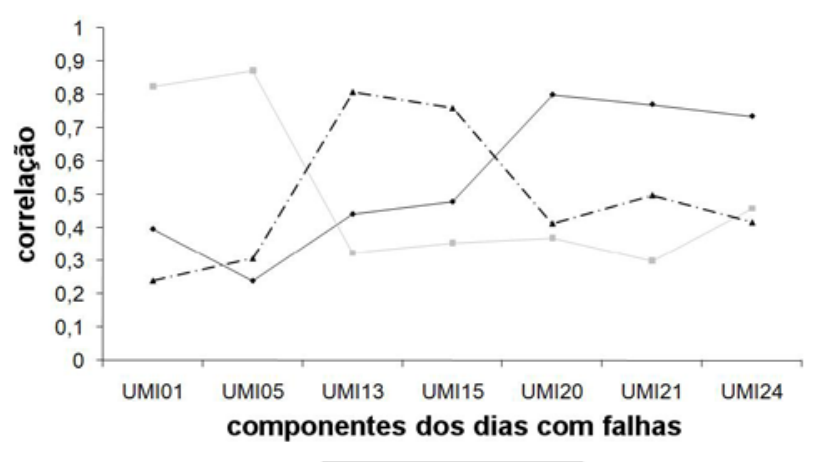

$\rightarrow \mathrm{CP} 1=\mathrm{CP} 2 \rightarrow \mathrm{CP} 3$

Figura 11 - Série temporal dos scores: (a)componentes zonal e meridional do vento em $200 \mathrm{hPa}$, (b)componentes zonal e meridional do vento em 925 $\mathrm{hPa}$, temperatura em $925 \mathrm{hPa}$ e umidade específica em $925 \mathrm{hPa}$ (La Ninã). 
Tabela 5 - Agrupamento de variáveis segundo a ACP para os eventos de falhas no período La Nina (LN): CP1.

\begin{tabular}{ccccccc}
\hline DIA 01 & DIA 05 & DIA 13 & DIA 15 & DIA 20 & DIA 20 & DIA 26 \\
\hline $\mathrm{U}_{200} ;$ & $\mathrm{U}_{200} ; \mathrm{U}_{500}$ & $\mathrm{U}_{200} ; \mathrm{U}_{500}$ & $\mathrm{U}_{200} ; \mathrm{U}_{500}$ & $\mathrm{U}_{200} ; \mathrm{U}_{500}$ & $\mathrm{U}_{200} ; \mathrm{U}_{500}$ & $\mathrm{U}_{200} ; \mathrm{U}_{500}$ \\
$\mathrm{U}_{925}$ & $\mathrm{U}_{925}$ & $\mathrm{U}_{925}$ & $\mathrm{U}_{925}$ & $\mathrm{U}_{925} ; \mathrm{T}_{925} ;$ & $\mathrm{U}_{925} ; \mathrm{T}_{925} ;$ & $\mathrm{U}_{925} ; \mathrm{T}_{925} ;$ \\
& & & & $\mathrm{q}_{925}$ & $\mathrm{q}_{925}$ & $\mathrm{q}_{925}$ \\
\hline
\end{tabular}

Conforme discutido no caso EL, essa é uma condição extremamente favorável para formação e desenvolvimento de $\mathrm{SC}$ na região. A maior diferença entre as duas situações (EL e $\mathrm{LN})$ é extensão da área com alto teor de umidade.

A CP2 da temperatura em $925 \mathrm{hPa}$ (Figura 13) mostra um dipolo em $10^{\circ} \mathrm{S}$. Esse padrão contribui para geração do gradiente de pressão e conseqüentemente intensificação da circulação nos baixos níveis.

\section{CONCLUSÕES}

As relações entre variáveis meteorológicas em ocorrências de descargas atmosféricas e interrupções no fornecimento

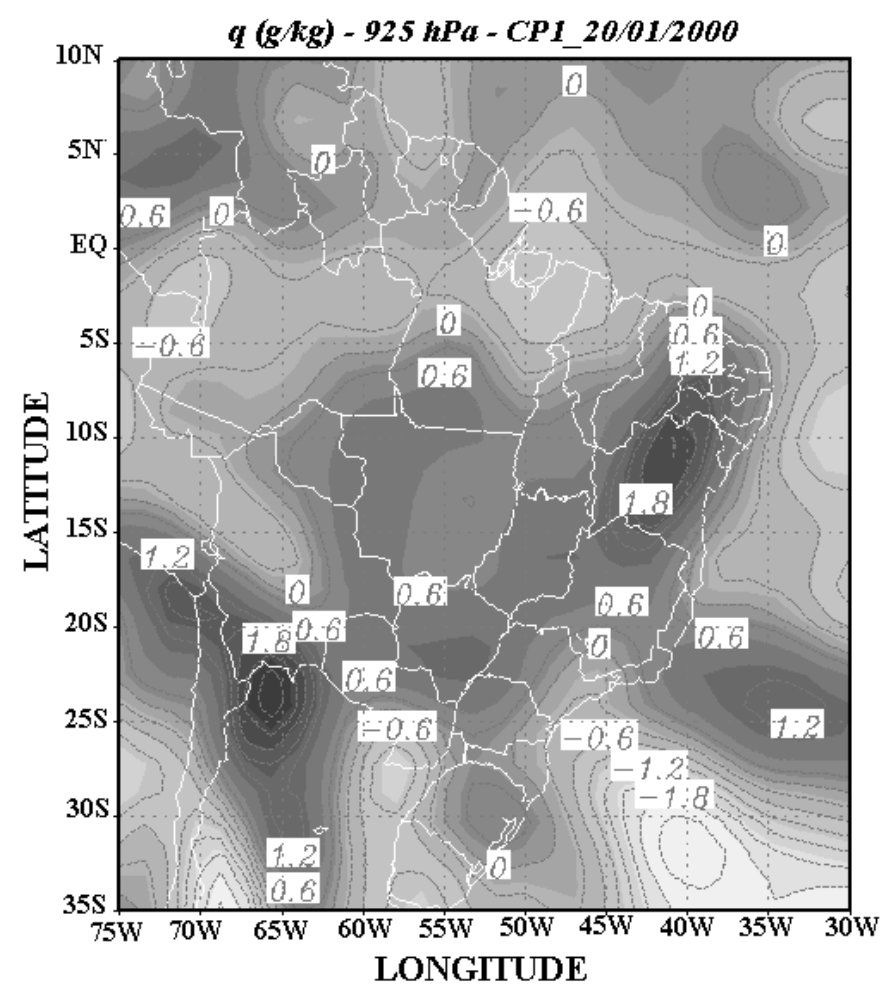

Figura 12 - Configuração espacial da CP1 da umidade específica para o evento 20 .

de energia, foram avaliadas com o objetivo de auxiliar na identificação de padrões atmosféricos associados com atividade convectiva intensa na área da CHESF, em episódios de El Niño (EL), La Niña (LN).

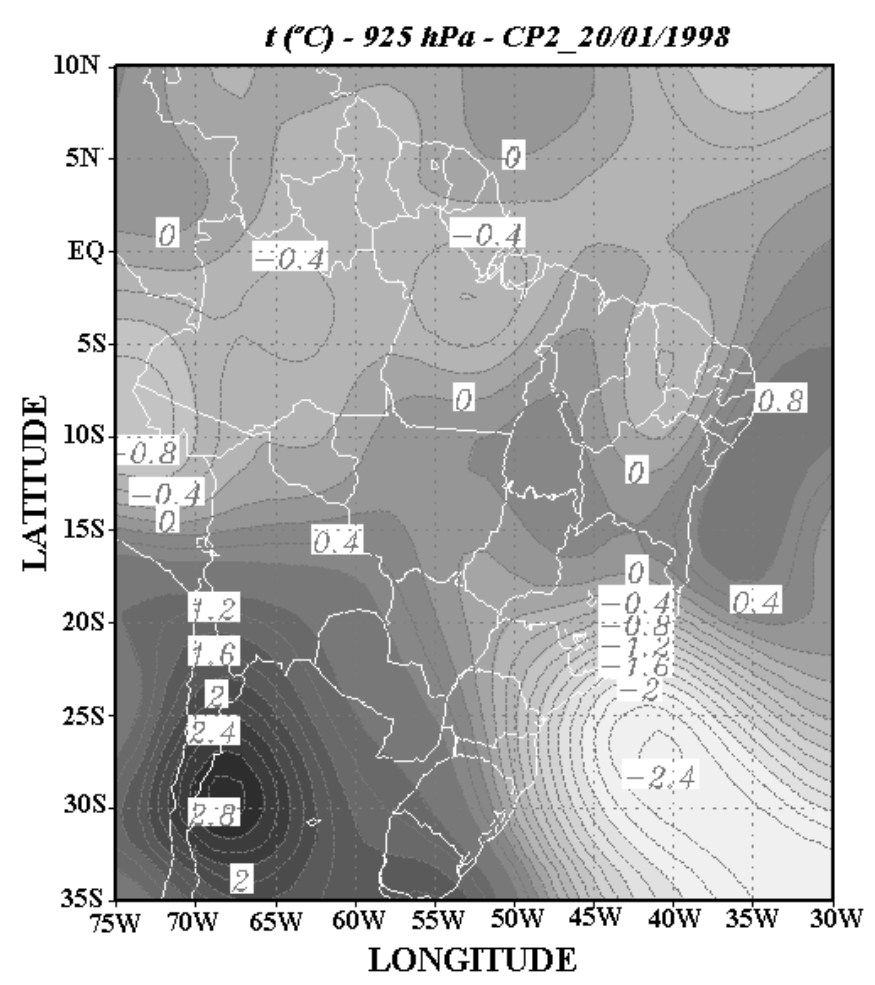

Figura 13- Configuração especial da $\mathrm{CP} 2$ da temperatura do ar para o evento 20 .

Foi verificado que os eventos de falha na transmissão de energia elétrica do sistema CHESF, ocorridos nos meses de dezembro de 1997 e janeiro de 2000 , foram causados pelo desenvolvimento de atividade convectiva intensa decorrente da ação de VCAN.

Através da ACP verificou-se que para os eventos de $E N$, existe forte associação entre as variáveis $U_{200}, U_{500}, V_{925}$ (vento zonal em 200 e $500 \mathrm{hPa}$ e vento meridional em $925 \mathrm{hPa}$ ) e umidade específica em $925 \mathrm{hPa}$. Já para os eventos de LN os grupos caracterizados pela CP1 mostram forte associação entre as variáveis $\mathrm{U}_{200}, \mathrm{U}_{500}, \mathrm{U}_{925}$ (vento zonal em 200, $500 \mathrm{e}$ $925 \mathrm{hPa}$ ), umidade específica e temperatura do ar em $925 \mathrm{hPa}$. Estas características representam um indicativo de que estes são elementos importantes na geração e desenvolvimento de $\mathrm{SC}$ intensos.

A ACP foi eficiente na determinação de configurações espaciais sob o domínio analisado associadas com anomalias de vento, temperatura e umidade nos eventos tempestade e, 
portanto, representa um recurso a mais no conhecimento sobre atividade convectiva intensa em situações climáticas distintas (episódios de EL e LN).

Os resultados confirmam características ambientais importantes associadas com tempestades intensas, tais como vapor d água abundante na baixa atmosfera (anomalias positivas de umidade) e ventos intensos nos baixos níveis e variação substancial do vento com a altura.

Embora bastante satisfatórios, os resultados não devem ser considerados como decisivos já que as análises apresentadas referem-se a um estudo de caso utilizando dados de dezembro de 1997 sob a influência de El Niño e dados de janeiro de 2000 sob a influência de La Niña. Entretanto, os indicativos obtidos são encorajadores no sentido de dar continuidade ao estudo apresentado.

\section{AGRADECIMENTOS}

Os autores agradecem a CHESF (Companhia Hidro Elétrica do São Francisco) pelo fornecimento dos dados de descargas atmosféricas, ao Dr. José Maurício de Barros Bezerra, professor adjunto do curso de Engenharia Elétrica da Universidade Federal de Pernambuco por sua valorosa contribuição ao longo do desenvolvimento deste trabalho, aos Revisores e ao Corpo Editorial da Revista Brasileira de Meteorologia pelas sugestões construtivas, ao CNPq (Processo: 480266/2004-2) e a CAPES pela concessão da bolsa de mestrado

\section{REFERÊNCIAS}

ARAGÃO, J.O.R. O impacto do ENSO e do Dipolo do Atlântico no Nordeste do Brasil. Bulletin de l'Institut français d'études andines, Lima, v. 27, n.3, p. 839-844, 1998.

BARBOSA, T.F. CORREIA, M.F. Sistemas convectivos intensos no semi-árido brasileiro: o controle da grande escala (Intense convective systems in semiarid Northeast Brazil: the large-scale control). Revista Brasileira de Meteorologia, v.20, p.395-410, 2005.

CHESF. Companhia Hidro Elétrica do São Francisco. A companhia. Disponível em: <http:/www.chesf.gov.br/ acompanhia_visaomissao.shtml $>$.Acesso em: 15 mai. 2003.

CORREIA, M.F.; SILVA DIAS, M.A. F; SILVA ARAGÃO, M.R. Soil occupation and atmospheric variations over Sobradinho Lake area. Part two: a regional modeling study. Meterology and Atmospheric Phisics, v. 94, p. 115-128, 2006.

FARIAS, W. R. G. Descargas atmosféricas e falhas no sistema de transmissão da CHESF em episódios de El Niño e La Niña: uma aplicação da análise de componentes principais. 2005. 135 p. Dissertação (Meteorologia) - Universidade Federal de Campina Grande, Campina Grande, 2005.
FOURNIER, A. Introduction to Orthonormal Wavelet Analysis with Shift Invariance: Application to Observed Atmospheric Blocking Spatial Structure. Journal of the Atmospheric Science, v. 57, p. 3856-3880, Dec. 2000.

FUNCEME. Fundação Cearence de Meteorologia e Recursos Hídricos. Informações sobre La Niña. Disponível em: $<$ http://www.funceme.br/demet/la_nina/nina.htm $>$. Acesso em: 04 Ago. 2003.

ESPINOZA, E.S. Distúrbios Ondulatórios de Leste na Região Tropical. Climanalise Especial 10 Anos. Campos de Jordão. Out. 1996.

GANDU, A.W.; SILVA DIAS, P. L. Impact of tropical heat sources on the South American tropospheric upper circulation and subsidence. Journal of Geophysics Research., v. 103, p. 6001-60015, 1998.

KOUSKY, V.E.; GAN, M.A. Upper tropospheric cyclonic vortices in the tropical South Atlantic. Tellus, v. 33, p. 538$551,1981$.

NOBRE, P.; SHUKLA J. Variations of sea surface temperature, wind stress, and rainfall over the tropical Atlantic and South America, Journal of Climate, v.9, n.19, p.2464-2479, Oct. 1996.

SATYAMURTY, P.; NOBRE, C.A.; DIAS, P.L.S. Meteorology of the south hemisphere. American Meteorology Society, Boston, v. 27, n.49, p. 119 - 139, Dec. 1998.

SILVA ARAGÃO, M.R; CORREIA, M.F.; ARAÚJO, H.A. Characteristic of C-Band meteorological radar echoes at Petrolina, Northeast Brazil. Journal of Climate, v.20, p. 279-298, 2000.

UVO, C.B. A Zona de Convergência Intertropical (ZCIT) e sua relação com a precipitação da Região Norte do Nordeste Brasileiro. 1989. 99 f. Dissertação (Meteorologia) - Instituto Nacional de Pesquisas Espaciais, São José dos Campos, 1989. 